\title{
Managing Downside Risk With Upside Volatility: Enhancing The Performance Of An Investment Portfolio With Managed Futures
}

\author{
Ian Hudson, Nova Southeastern University
}

\begin{abstract}
Managed futures refer to the active trading of forward and futures contracts on physical commodities, financial assets, and currencies. Since managed futures have little to no correlation with stocks and bonds, advocates claim this asset class provides much-needed diversification, allowing investors to profit from price volatility. However, naysayers believe this volatility makes managed futures a highly risky investment. Do the unique features of this asset class make it worthy of inclusion in an investment portfolio? This article asserts managed futures provide investment managers a powerful tool to manage downside risk by capitalising on upside price volatility.
\end{abstract}

\section{INTRODUCTION}

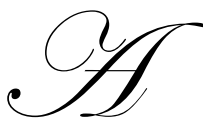

ccording to Anson (2004), downside risk is an investor's greatest fear. This risk is viewed in terms of the possibility of loss below a minimum acceptable return (Ang, 2006). In the past, investors were advised to include foreign stocks and bonds in their portfolios as a protective measure. Due to globalisation, foreign and domestic markets have become synchronised. Therefore, international debt and equity diversification does not offer the protection it once did.

Managed futures are a tool used by professional money managers known as commodity trading advisors (CTAs) to manage client assets on a discretionary basis. Investors have access to commodity markets by means of futures, forwards and options contracts on physical commodities and financial instruments. CTAs either pool funds or invest for individual accounts in a wide range of derivative instruments-from agricultural commodities, metals, and energy to currencies, stock indices and interest rates. They pursue a market-momentum or trend-following trading strategy and accordingly take long or short positions to capitalise on price volatility. Many in the futures industry market managed futures as portfolio insurance (Chance, 1994). However, it is not insurance in the common understanding of the term. A better term is "portfolio assurance" since the goal of any managed futures contract is to remain above a pre-determined minimum or floor value.

\section{LITERATURE REVIEW}

Industry and academic research agree regarding the inclusion of a managed futures component to a stock and bond portfolio and its contribution to overall diversification. In a study covering a 25-year period, Goldman Sachs (2003) concluded, "allocating only $10 \%$ of a securities portfolio to commodities, investors can vastly improve their performance." Research conducted by the Chicago Mercantile Exchange (1999) yielded a similar sentiment. According to the CME study, "Portfolios with as much as $20 \%$ of assets in managed futures yielded up to $50 \%$ more than a portfolio of stocks and bonds alone." Findings published by the Chicago Board of Trade (1999) demonstrated a portfolio with the greatest returns and least risk was comprised $45 \%$ stocks, $35 \%$ bonds, and $20 \%$ managed futures, while a portfolio exhibiting the greatest risk and least returns contained $55 \%$ stocks, $45 \%$ bonds, and $0 \%$ managed futures. 
Kat (2002) confirmed Commodity Trading Advisors are trend followers as proven by their highly significant, positive correlation with the Mount Lucas Management (MLM) Index, which tracks commodity futures. He noticed their trading strategies capture large price movements. Kat also determined the inclusion of managed futures in a stock and bond portfolio is a cost effective means of reducing risk without undesired effects on skewness and kurtosis.

Irwin and Yoshimaru (1996) researched the widely held belief: managed futures trading increases volatility and suppresses price discovery resulting in price signal 'noise'. The authors performed a regression analysis of managed futures trading for the period of 1 December 1988 through 31 March 1989. The correlation coefficient was significantly different from zero in only three instances - in fact, less than the amount of expected significance based on random occurrence. They also discovered a significant, positive correlation of managed futures trading with market trading volume. They found no evidence CTAs trade during illiquid market periods. Indeed, the opposite is true: since CTAs trade during periods of liquidity, price volatility is decreased. No significant relationship between managed futures trading and price volatility in the futures markets was discovered. Instead, this volatility was attributed to a number of other factors such as the dramatic increase of money in managed futures accounts. As a result, CTAs control a substantial amount of the speculative trading capital in the futures market.

Schneeweis and Spurgin (2003) note the following factors are based on common sources of return to managed futures trading strategies:

- $\quad$ A natural return to owning financial and real assets: represented by nominal value of stocks (Russell 2000) and bonds (Lehman U.S. Aggregate and High Yield)

- $\quad$ Flexibility to use both long and short positions to benefit from market timing skill—represented by absolute value of the monthly returns of the underlying asset markets

- $\quad$ Arbitrage opportunities as a result of market inefficiencies.

These observations are consistent with the notion the risk-return structure of managed futures differs from stock and bonds. The correlations between various CTA indices and the nominal and absolute values of market factors are consistent with previous academic research. CTA returns show low correlation with stock and bond market factors.

According to Kung and Pohlman (2004), active investment managers provide two types of return: the return generated from exposure to the market (beta) and the return which is a result of selection-skill. (Alpha is the risk-adjusted excess return generated by the fund over the return of the benchmark-a true alpha strategy is independent of beta. A fund will have positive alpha if it produces an excess return over the benchmark on a riskadjusted basis.) Brorsen (1998) found evidence of performance persistence of managed futures due to the skill of individual fund managers. This is known as portable alpha, the inclusion of a non-correlated strategy within an existing portfolio in order to improve risk-adjusted returns. Brorsen demonstrated the performance persistence is statistically significant and large relative to the mean. This finding concurs with Schneeweis and Spurgin (2003): CTAs profit by taking advantage of arbitrage opportunities in the futures market.

\section{METHODOLOGY}

Market data was collected from the following databases: the Center for Research in Security Prices (CRSP), Standard \& Poor's COMPUSTAT and the Center for International Securities and Derivatives Markets (CIDSM). Stock market performance is measured by monthly returns of the S\&P 500 Index. Nominal returns on the Lehman Government Bond Index were used as a proxy for the bond portfolio. (This index is a dollar-weighted index of treasury and government-agency bonds with maturities greater than one year). Managed Futures are represented by the CISDM CTA Index, the Credit Suisse First Boston (CSFB) Tremont Index, Barclay CTA Index, and the S\&P Managed Futures Index. The three-month U.S. Treasury bill is representative of cash.

Statistical tests include descriptive risk and return characteristics, correlation analysis, and multiple regressions. The data collected is utilised to produce a deviation analysis, asset class comparison, and asset 
correlation matrix. This is done in an effort to demonstrate the effectiveness of managed futures as a risk-reduction tool and return performance enhancer. Downside deviation is utilised to perform risk analysis instead of standard deviation and the Sharpe Ratio.

\section{RESULTS}

Despite being the most widely accepted measure of risk, standard deviation is misunderstood and misused. It is instead a measure of price volatility - a statistical measure of the range of the actual performance of the fund manager around an average. Many investors reason since managed futures have greater price volatility than stocks and bonds, greater risk is involved as well. Much of this argument is based on a comparison of overall standard deviation. Superficially, standard deviation comparisons cast managed futures as a riskier investment.

The usefulness of standard deviation as a comparative measure of risk is predicated on the assumption the investments being compared share similar return distributions. As noted by Warsager \& Pescatore (1998), standard deviation is misleading when used to measure risk between differing asset classes because it assumes a normal distribution. It interprets any difference from the average, above or below, as bad. This notion is contrary to the way most investors feel about returns. Upside volatility, which is used to accomplish investment objectives, is penalised because it is equated with the value-destroying downside volatility. The Sharpe Ratio is also an unacceptable measure of risk since it utilises standard deviation. For the purposes of this paper, standard deviation will be used as a representation of volatility.

Downside deviation considers only returns falling below a defined Minimum Acceptable Return (MAR) rather then the arithmetic mean. For example, if the MAR is $10 \%$, the downside deviation would measure the variation of each period below 10\%. (Standard deviation, on the other hand, would take only losing periods, calculate an average return for the losing periods, and then measure the variation between each losing return and the losing return average).

Figure 1 compares the average monthly deviations of the S\&P 500 Index and the Dow 30 Index during up and down months with corresponding values for the Barclay CTA Index from 1 January 1980 through 31 January 2004. The volatility of the S\&P 500 and Dow 30 returns in up and down periods is consistent. This is typical of a normal distribution where the returns are distributed symmetrically.

Figure 1: Average Monthly Deviations (January, 1980 - January, 2005)

\begin{tabular}{|c|c|c|c|}
\hline & Upside Deviation & Downside Deviation & Average $\underline{\text { Returns }}$ \\
\hline S\&P 500 Index & 0.99 & 1.51 & 14.54 \\
\hline Dow 30 Index & 0.96 & 1.54 & 11.98 \\
\hline Barclay CTA Index & 2.12 & 0.92 & 12.59 \\
\hline
\end{tabular}

However, an examination of the upside and downside volatility of the Barclay CTA Index does not show a similar consistency. Instead the sizeable difference supports the argument CTA returns are distributed asymmetrically and upside volatility is significantly greater than downside volatility. The basis for these asymmetrical returns is rooted in trading methodology. In order to be successful, a trader must cut his losses before they become insurmountable. Equally important is his ability to stay onboard with large price swings, allowing profits to run.

During the study period, upside volatility for the S\&P 500 was less than $1 \%$ versus $2.12 \%$ for the Barclay CTA Index. Downside volatility for the S\&P 500 was $1.51 \%$ versus less than $1 \%$ for the CTA. Although overall price volatility for managed futures was higher than equities, the higher volatility seems was limited to months in which CTAs were making money. During losing periods, managed futures volatility was actually slightly less than stock market volatility. 
As shown by Figure 2, the S\&P Managed Futures Index outperformed other asset class indices with an annualised return of $13.7 \%$ from 1998 - 2002. A $\$ 1,000$ investment in managed futures, bonds or stocks would have resulted in $\$ 1,900, \$ 1,438$ and $\$ 971$ respectively. Unlike the equity indices or the Lehman Brothers Bond indices, the S\&P MFI had positive returns every year.

Figure 2: S\&P Managed Futures Index vs. Various Asset Classes (1998 - 2002)

\begin{tabular}{|c|c|c|c|c|c|c|c|}
\hline & $\underline{\mathbf{1 9 9 8}}$ & $\underline{\mathbf{1 9 9 9}}$ & $\underline{\mathbf{2 0 0 0}}$ & $\underline{\mathbf{2 0 0 1}}$ & $\underline{\mathbf{2 0 0 2}}$ & $\begin{array}{c}\text { Average } \\
\text { Annual Return }\end{array}$ & $\begin{array}{c}\text { Standard } \\
\text { Deviation }\end{array}$ \\
\hline S\&P Managed Futures Index & $21.6 \%$ & $6.3 \%$ & $15.9 \%$ & $5.7 \%$ & $20.0 \%$ & $13.7 \%$ & $16.6 \%$ \\
\hline U.S. Treasury Bills & $4.8 \%$ & $4.7 \%$ & $5.9 \%$ & $3.4 \%$ & $1.6 \%$ & $4.1 \%$ & $0.4 \%$ \\
\hline $\begin{array}{c}\text { Lehman Brothers } \\
\text { U.S. Treasury Bond Index }\end{array}$ & $8.7 \%$ & $-0.8 \%$ & $11.6 \%$ & $8.4 \%$ & $10.3 \%$ & $7.5 \%$ & $3.3 \%$ \\
\hline S\&P 500 Index & $28.6 \%$ & $21.0 \%$ & $-9.1 \%$ & $-11.9 \%$ & $-22.1 \%$ & $-0.6 \%$ & $18.9 \%$ \\
\hline
\end{tabular}

Managed futures had a standard deviation of $16.60 \%$. However, it was not as high as the $18.90 \%$ standard deviation of the S\&P 500. This is further demonstrates high price volatility in managed futures is beneficial and not indicative of greater risk. Indeed, price volatility is put to work for the investor: on the upside it is absorbed in generating actual returns while on the downside, it is effectively controlled and is therefore significantly lower.

Further evidence of the protection provided by managed futures is a tendency to generate large positive returns in down stock markets. As seen in Figure 3, in the ten months the S\&P 500 had its worst returns, the S\&P Managed Futures Index had positive returns.

Figure 3: S\&P 500 vs. S\&P Managed Futures Index (9/98 - 4/02)

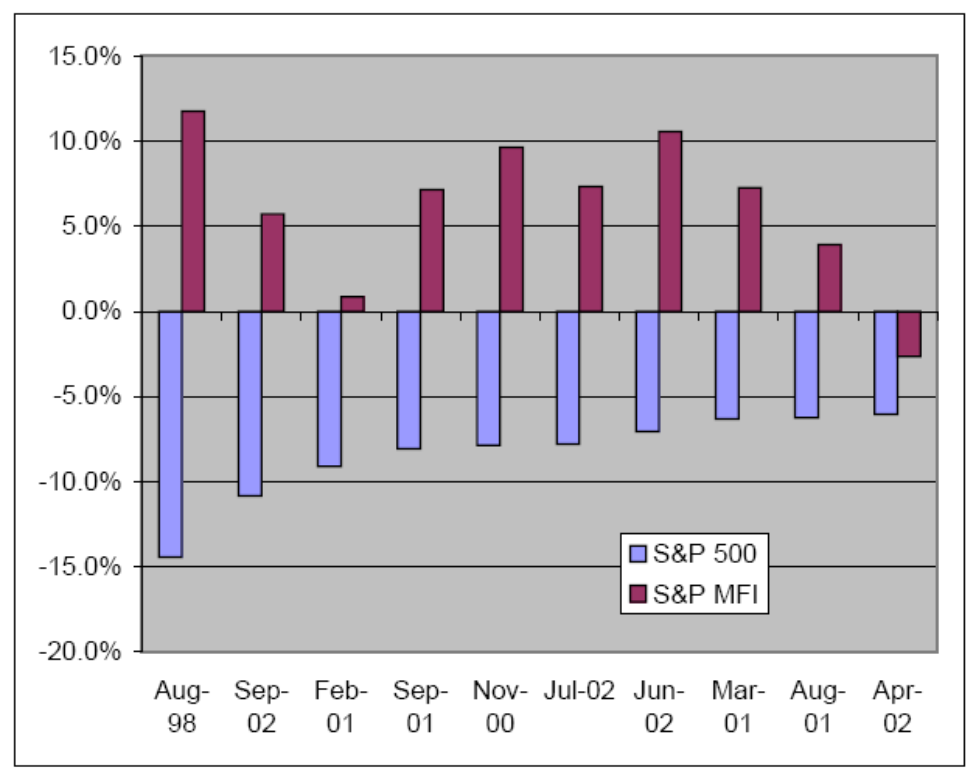

Source: Standard \& Poor's, a division of The McGraw-Hill Companies, Inc. 


\section{Correlation Between Asset Classes}

Closely related to the concept of diversification is the analysis of the performance of different investments relative to each other, otherwise known as correlation. Combining asset classes with different patterns of return may create a portfolio with lower risk levels than the individual investments themselves (e.g. one asset class is performing well while another is in decline. Modern Portfolio Theory (Markowitz, 1959) makes a strong case for the use of managed futures advocating a more efficient investment portfolio can be created by diversifying among asset categories with low to negative correlations. Figure 4 charts correlation among stocks, bonds and managed futures.

Figure 4: Correlation Coefficients for Various Asset Classes (1982 - 2005)

\begin{tabular}{|c|c|c|c|c|c|c|}
\hline & $\begin{array}{c}\text { CISDM } \\
\text { CTA Index }\end{array}$ & $\begin{array}{c}\text { S\&P 500 } \\
\text { Index }\end{array}$ & $\begin{array}{c}\text { Russell 2000 } \\
\text { Index }\end{array}$ & $\begin{array}{c}\text { U.S. } \\
\text { Treasury } \\
\text { Bills }\end{array}$ & $\begin{array}{c}\text { U.S. } \\
\text { Treasury } \\
\text { Notes }\end{array}$ & $\begin{array}{c}\text { U.S. } \\
\text { Treasury } \\
\text { Bonds }\end{array}$ \\
\hline CISDM CTA Index & 1.00 & -0.01 & -0.08 & 0.09 & 0.04 & 0.11 \\
\hline S\&P 500 Index & -0.01 & 1.00 & 0.85 & -0.02 & 0.34 & 0.39 \\
\hline Russell 2000 Index & -0.08 & 0.85 & 1.00 & -0.10 & 0.15 & 0.19 \\
\hline U.S. Treasury Bills & 0.09 & -0.02 & -0.10 & 1.00 & 0.23 & 0.14 \\
\hline U.S. Treasury Notes & 0.04 & 0.34 & 0.15 & 0.23 & 1.00 & 0.92 \\
\hline U.S. Treasury Bonds & 0.11 & 0.39 & 0.19 & 0.14 & 0.92 & 1.00 \\
\hline
\end{tabular}

Correlations computed using monthly returns. Significance is at the 0.05 level.

In general, the correlation between managed futures and the other asset classes is near zero. In fact, the CISDM CTA Index is negatively correlated with the S\&P 500 Index and the Russell 2000 Index. Thus, the lack of correlation lends further support to managed futures as an enhancer of investment portfolio performance.

\section{Does Investing In Losers Make Sense?}

Schwager (1996) argues investing with a fund manager after recent losses is a good idea since Commodity Trading Advisors profit by exploiting arbitrage opportunities and returns are reduced when more money is devoted to a trading system. Gorton and Rouwenhorst (2004) assert an investment in commodity futures can earn a positive return even when spot commodity prices are falling. The authors questioned if managed futures provided a hedge against inflation. Since managed futures represent an expectation on commodity prices, they are directly linked to the components of inflation. Futures prices include information regarding trends in commodity prices. These prices rise and fall with unexpected deviations from components of inflation. Managed futures have an opposite exposure to inflation compared to stocks and bonds. These asset classes are negatively correlated with inflation while managed futures exhibit a positive correlation. Economists agree this is the reason why futures perform well when stocks and bonds do not. If the managed futures price is set above the expected future spot price, the seller of managed futures earns a risk premium. Keynes (1930) theory of normal backwardation lends further support to the notion of money being made despite investing in losers. By "backwardating" the futures price relative to the expected future spot price, investors receive a risk premium from producers for assuming the risk of future price fluctuations.

\section{DISCUSSION}

The addition of managed futures to a stock/bond portfolio appears to improve return performance without greater risk. Recent findings show holding stocks has the same volatility as holding managed futures investments. Researchers at the Center for International Security and Derivative Markets (CISDM) discovered the average Commodity Trading Advisor has a variance roughly equal to an individual stock in the S\&P 500, and a managed futures portfolio has a standard deviation similar to the overall S\&P 500. The risk/return relationships were also present. A portfolio of six CTAs with twice the variance of the S\&P 500 generated approximately twice the return. 
This analysis and comparison of upside and downside volatility possibly provides a deeper understanding of the contributing forces defining the nature of the return stream.

\section{CONCLUSION}

Managed futures should enhance portfolio performance due to high returns and very low correlation with the performance of stocks and bonds - these unique features increase the risk-adjusted return. A successful exploitation of upside volatility represents a proactive stance on the part of investment managers.

\section{REFERENCES}

1. $\quad$ Ang, A., Chen, J. \& Xing, Y. (2006). Downside Risk. The Review of Financial Studies. 19, 1191-1239.

2. Anson, M. (2004). Managing Downside Risk in Return Distributions Using Hedge Funds, Managed Futures and Commodity Indices. Commodity Trading Advisors: Risk, Performance Analysis and Selection. 220 - 229. New York: Wiley Finance.

3. Brorsen, B. W., \& Townsend, J. (2002). Performance Persistence for Managed Futures. The Journal of Alternative Investments. 4 (4), 57-65.

4. Chance, D.M. (1994). Managed Futures and Their Role in Investment Portfolios. The Research Foundation of the Institute of Chartered Financial Analysts. Charlottesville, Virginia.

5. Chicago Board of Trade. Managed Futures: Portfolio Diversification Opportunities.

6. Chicago Mercantile Exchange. (1999). Question and Answer Report: Managed Futures Accounts. Report No. M584/10M.1299.

7. Goldman Sachs International and Russell Investment Group. (2003). Report on Alternative Investing by Tax-Exempt Organizations. A Survey of Organizations in North America, Europe, Australia and Japan. New York.

8. Gorton, G. \& Rouwenhorst, K. Geert. (2004). Facts and Fantasies about Commodity Futures. NBER Working Papers 10595, National Bureau of Economic Research, Inc.

9. Hedges, J.R. IV. (2005). Hedges on Hedge Funds: How to Successfully Analyze and Select an Investment. 79-83. New Jersey: Wiley Publishing.

10. Irwin, Scott and Yoshimaru, Satoko. (1996) Managed Futures Trading and Futures Price Volatility. Managed Derivatives Research Foundation.

11. Kat, H.M. (2002). Managed Futures and Hedge Funds: A Match Made in Heaven. White Paper, ISMA Centre, University of Reading, UK.

12. Keynes, J.M. (1930). A Treatise on Money, Vol. 2. Macmillan: London.

13. Kung, E. \& Pohlman, L. (2004). Portable Alpha: Philosophy, Process and Performance. Journal of Portfolio Management 30 (3), 78-87.

14. Schneeweis, T. \& Spurgin, R. (2003). Quantitative Analysis of Hedge Fund, Managed Futures, Mutual Fund Return and Risk Characteristics. Evaluating and Implementing Hedge Fund Strategies. $3^{\text {rd }}$ edition. University of Massachusetts, Amherst.

15. Schwager, J. (1996). Managed Trading: Myths and Truths. New York: John Wiley \& Sons.

16. Warsager, R. and J. Pescatore. (1998) The Positive Skewness of Managed Futures Volatility. Bulletin of Managed Futures Research. 